Revista Destaques Acadêmicos, Lajeado, v. 12, n. 1, 2020. ISSN 2176-3070

DOI: http://dx.doi.org/10.22410/issn.2176-3070.v12i1a2020.2521

http://www.univates.br/revistas

\title{
GOVERNOS DIGITAIS: PADRONIZAÇÃO E MODERNIZAÇÃO DO PORTAL DA TRANSPARÊNCIA E DADOS ABERTOS DO MUNICÍPIO DE LAJEADO
}

\author{
Fabrício Pretto ${ }^{1}$, Mathias Horn
}

Resumo: No cenário público, o acesso à informação é um fator importante para a população em geral. Os cidadãos sentem-se seguros e confiantes ao saber a finalidade destinada ao dinheiro pago em impostos e tarifas. Por meio de lei, municípios, estados e federação obrigaram-se a publicar mensalmente informações relacionadas com gastos oriundos de despesas com licitações, folha de pagamento e empenhos, por exemplo. O site do Portal da Transparência busca oferecer acesso às informações por consultas e filtros. No entanto, o formato dos dados não é padronizado, sendo apresentados em arquivos Txt, Pdf, Csv ou somente em vídeo, sem exportação. Como forma de facilitar o acesso aos dados públicos, o objetivo desse trabalho foi desenvolver uma nova proposta de portal da transparência. Para essa nova proposta foi considerado uma interface de fácil compreensão, consultas em vídeo e também exportações, permitindo ao cidadão simplicidade nas consultas. Além disso, com o intuito de fomentar novos negócios por meio do acesso à informação, implementou-se um recurso denominado Web Service, para acesso via software. Nessa segunda modalidade de acesso, desenvolvedores podem obter as informações de maneira simples e padronizada, permitindo avaliação dos dados, identificando padrões e estabelecendo métricas. $\mathrm{O}$ sistema desenvolvido foi validado por um conjunto de usuários que julgou o novo portal mais eficiente e intuitivo.

Palavras-chave: Governos digitais, Transparência, Dados abertos.

\section{Introdução}

A tecnologia está revolucionando os meios de informação. Cada vez mais, as pessoas deixam de buscar conhecimento nos meios tradicionais e passam a procurá-lo em meios mais rápidos e com maior mobilidade, como

1 Mestre em Ciência da Computação. Professor Universidade do Vale do Taquari - Univates Lajeado. Atuante nos cursos presenciais de Sistemas de Informação, Engenharia de Software e Engenharia da Computação. Professor e conteudista dos cursos de informática EAD da IES. Atuação na extensão como voluntário e coordenador do projeto Robótica Educacional. 
a Internet. Com as informações referentes à administração pública não é diferente.

Visando passar uma imagem transparente, os órgãos públicos têm ajustado seus sistemas para atender às solicitações do cidadão. Aliado a isso, está a legislação. Desde a Lei de Acesso à Informação, regulamentada em 2011, o Brasil tem sancionado leis que estimulam a transparência, os dados abertos e a accountability. Segundo a Global Open Data Index (2016), o país ocupa a $8^{\text {a }}$ posição do ranking de abertura de dados ao público.

Apesar desses bons índices, como destaca Ribeiro e Almeida (2013), a sociedade está cada vez mais exigente quanto à transparência nos governos, sendo que o simples acesso aos registros já não é o suficiente. $O$ usuário quer a informação processada e os dados disponíveis para compartilhamento e reutilização.

Nesse contexto, os sistemas de informação devem se reinventar para atender os anseios da população. $\mathrm{O}$ presente projeto teve como proposta fornecer e validar um novo meio de acesso à informação para o município de Lajeado. Meio esse que possa fornecer um acesso mais completo e intuitivo ao cidadão, e cujos dados estejam em formatos amigáveis à utilização em aplicações e projetos futuros.

\section{Referencial teórico}

Tendo em vista um embasamento teórico para o trabalho, neste capítulo são apresentadas as referências bibliográficas necessárias para a sua compreensão.

\subsection{Governos digitais}

Um Governo é considerado digital quando, através do uso de tecnologias da informação, consegue modificar a sua relação com cidadãos, empresas e outras esferas do governo. Esse alinhamento da tecnologia com o governo propicia inúmeros benefícios para a administração e para a sociedade, dentro os quais vale destacar: índices menores de corrupção, maior transparência, mais comodidade, aumento de receitas e redução de custos (WORLD BANK, 2004, apud GRÖNLUND e HORAN, 2005).

Grönlund (2002) complementa que, os governos adotam estratégias digitais vislumbrando 3 objetivos principais:

1. Ter um governo mais eficiente;

2. Fornecer melhores serviços para o cidadão;

3. Melhorar o processo democrático.

De acordo com Gartner (2018), os governos digitais podem ser classificados em 5 níveis de maturidade: 
Nível 1: Inicial (e-gov): O foco está em fornecer serviços de forma online, provendo facilidade e conveniência para o cidadão, e substituindo serviços manuais. $\mathrm{O}$ acesso a dados é extremamente limitado.

Nível 2: Aberto (Em Desenvolvimento): são os chamados dados abertos. Independente do primeiro nível, ou seja, o e-gov não precisa existir para haver dados abertos. Essas duas iniciativas geralmente são lideradas por equipes diferentes. Esse nível tem por finalidade fornecer transparência e poder de participação ao cidadão.

Nível 3: Definido (Foco em Dados): Há interesse em um maior aproveitamento dos dados para aplicações futuras. A organização não se limita a apenas prover dados ou escutar o cidadão. Existe um real interesse em fornecer dados úteis, para isso há o questionamento "quanto de nossos dados se encontram abertos?".

Nível 4: Gerenciado (Totalmente Digital): Os dados são utilizados e fluem entre as partes da organização de forma plena. Sua exploração gera serviços úteis para a população. Dado o nível de avanço, passam a surgir questionamentos quanto à privacidade e legalidade de vinculação dados pessoais. Para isso, devem ser cumpridas normas e regulamentações existentes.

Nível 5: Inteligente (Em Otimização): a cultura de dados abertos está enraizada nos setores da organização. Políticos influentes defendem a ideia. $\mathrm{O}$ foco está na manutenção e otimização do processo, que é bastante previsível.

\subsection{Dados abertos}

Dados abertos são dados não privados e não confidenciais que têm origem na esfera pública, e que são disponibilizados sem qualquer restrição de uso ou distribuição. Aqueles dados que possuem qualquer restrição de publicação, são excluídos. A área também pode abranger o setor privado, mas em sua essência, tem o enfoque no setor público (JANSSEN; CHARALABIDIS; ZUIDERWIJK, 2012).

O OpenGovData (2007), grupo composto por especialistas na área de dados abertos, definiu 8 princípios para os dados serem considerados abertos:

1. Completos: todos os dados, que não sofram de limitações de privacidade ou confidencialidade, devem ser tornados públicos. É encorajado que, artefatos existentes somente no meio físico, devem ser digitalizados;

1. Primários: os dados extraídos na origem, devem ser apresentados com o maior nível de granularidade possível, sem funções de modificação ou agregação;

2. Atuais: os dados devem ser publicados o mais rapidamente possível, a fim de manter o seu valor; 
3. Acessíveis: devem ser dispostos podendo atender as mais diversas formas de utilização de usuários ou negócios. Precisa atender padrões/formatos conhecidos de arquivos do mercado. Não é considerado acessível, o dado que puder ser obtido apenas através de web forms (formulários de páginas da internet);

4. Processáveis por máquinas: devem ser divulgados em formatos que permitam a automação, com a devida descrição do conjunto;

5. Não discriminatórios: qualquer um pode ter acesso aos dados, sem a necessidade de pedido ou identificação. Acessos anônimos devem ser permitidos, mesmo via proxy;

6. Não proprietários: devem ser divulgados em formato que não pertença a nenhuma empresa ou organização específica;

7. Livres de Licenças: respeitadas as exceções de privacidade e confidencialidade citadas anteriormente, os dados não devem estar sujeitos a nenhuma restrição de direito autoral, patente, propriedade intelectual ou segredo industrial.

Assim como todo avanço tecnológico, os dados abertos podem propiciar inúmeros benefícios à sociedade. Uma pesquisa feita por Janssen, Charalabidis e Zuiderwijk (2012) apontou respostas dos entrevistados, relacionando benefícios em 3 principais áreas: política/social, econômica e operacional/ técnica. Quanto ao retorno do investimento (ROI) os autores afirmam ser praticamente impossível de calcular, devido ao fato de que não é possível prever quais e quantas aplicações futuras irão utilizador os dados publicados. Em suma, a verdade é que os dados abertos em si, não possuem um valor, o valor passa a existir quando estes passam a ser utilizados. O Quadro 1 apresenta os benefícios relacionados às 3 principais áreas citadas na pesquisa.

Quadro 1 - Resumo de benefícios da implantação de dados abertos

\begin{tabular}{|l|l|}
\hline Categoria & Benefício \\
\hline Política/social & - Mais transparência \\
& - Responsabilidade democrática \\
& - Maior participação e auto capacitação dos cidadãos (usuários) \\
- Criação de confiança no governo \\
- Engajamento público \\
- Detalhamento de dados \\
- Igualdade de acesso aos dados \\
- Novos serviços governamentais para cidadãos \\
- Melhoria de serviços de cidadão \\
- Aumento da satisfação do cidadão \\
- Melhoria dos processos de elaboração de políticas \\
- Mais visibilidade para o provedor de dados \\
- Estimulação da evolução do conhecimento \\
- Criação de novos insights
\end{tabular}




\begin{tabular}{|c|c|}
\hline Categoria & Benefício \\
\hline Econômica & $\begin{array}{l}\text { - Crescimento econômico e estímulo à competitividade } \\
\text { - Estimulação da inovação } \\
\text { - Contribuição para a melhoria de processos, produtos e / ou } \\
\text { - serviços } \\
\text { - Desenvolvimento de novos produtos e serviços } \\
\text { - Uso da sabedoria das multidões: aproveitando a inteligência } \\
\text { do coletivo } \\
\text { - Criação de um novo setor que agregue valor à economia } \\
\text { - Disponibilidade de informações para investidores e empresas }\end{array}$ \\
\hline $\begin{array}{l}\text { Operacional/ } \\
\text { técnica }\end{array}$ & $\begin{array}{l}\text { - A capacidade de reutilizar dados / não ter que coletar os } \\
\text { mesmos dados novamente e neutralizá-los } \\
\text { - Otimização de processos administrativos } \\
\text { - Melhoria das políticas públicas } \\
\text { - Acesso à capacidade externa de resolução de problemas } \\
\text { - Tomada de decisão justa, permitindo comparação } \\
\text { - Acesso mais fácil aos dados e descoberta de dados } \\
\text { - Criação de novos dados com base na combinação de dados } \\
\text { - Verificações externas de qualidade dos dados (validação) } \\
\text { - Sustentabilidade dos dados (sem perda de dados) } \\
\text { - A capacidade de mesclar, integrar e mesclar dados públicos e } \\
\text { privados }\end{array}$ \\
\hline
\end{tabular}

Fonte: Do autor, adaptado de Janssen, Charalabidis e Zuiderwijk (2012).

\subsection{Decretos, Leis e Instruções Normativas que regulamentam a Transparência e os Dados Abertos}

Dado que o assunto é considerado recente no âmbito nacional, algumas leis e normativas passaram a ser regulamentadas, para que as cidades, estados e o país começassem a adotar medidas de transparência e abertura de dados. Dentre os quais podemos destacar:

- Lei n ${ }^{\circ} 12.527 / 2011$, de 18 de novembro de 2011 - Lei de Acesso à Informação;

- Decreto $\mathrm{n}^{\mathrm{o}}$ 7.724, de 16 de maio de 2012 - Regulamenta a Lei no ${ }^{\circ}$ 12.527;

- Instrução Normativa $\mathrm{n}^{\circ}$ 4, de 12 de abril de 2012 - Institui a Infraestrutura Nacional de Dados Abertos - INDA;

- Decreto de 15 de setembro de 2011 - Institui o Plano de Ação Nacional sobre Governo Aberto e dá outras providências;

- Decreto $\mathrm{n}^{\mathrm{o}}$ 8.638, de 15 de janeiro de 2016 - Institui a Política de Governança Digital;

- Decreto n ${ }^{\circ}$ 8.777, de 11 de maio de 2016 - Institui a Política de Dados Abertos do Poder Executivo Federal; 


\section{Metodologia}

Neste capítulo será abordada a metodologia utilizada para o alcance do objetivo do projeto.

\subsection{Etapas do Projeto}

Antes mesmo do início do projeto já havia o anseio por parte do autor de trabalhar com dados governamentais públicos. Houve um contato inicial com algumas prefeituras da região, sendo a do município de Lajeado uma das quais mostrou interesse em possuir um trabalho com tal temática. Logo, foram realizadas algumas reuniões presenciais com secretários e profissionais da área da TI da prefeitura. Após essas conversas ficou evidenciado que o município possuía um portal que atendia minimamente os requisitos necessário de transparência e abertura de dados.

A Figura 1 exibe a tela inicial do atual Portal da Transparência do Município de Lajeado. Nela é dada uma breve introdução sobre o funcionamento. No menu à esquerda, são disponibilizadas as opções de pesquisa por dados. Cada opção do menu possui uma apresentação para os dados de forma diferente. Alguns registros são exibidos somente em formato PDF, enquanto outros estão disponíveis em formulários da web. Os formulários da web também variam entre si, havendo mais de um formato de exibição.

Figura 1 - Atual Portal da Transparência do Município de Lajeado

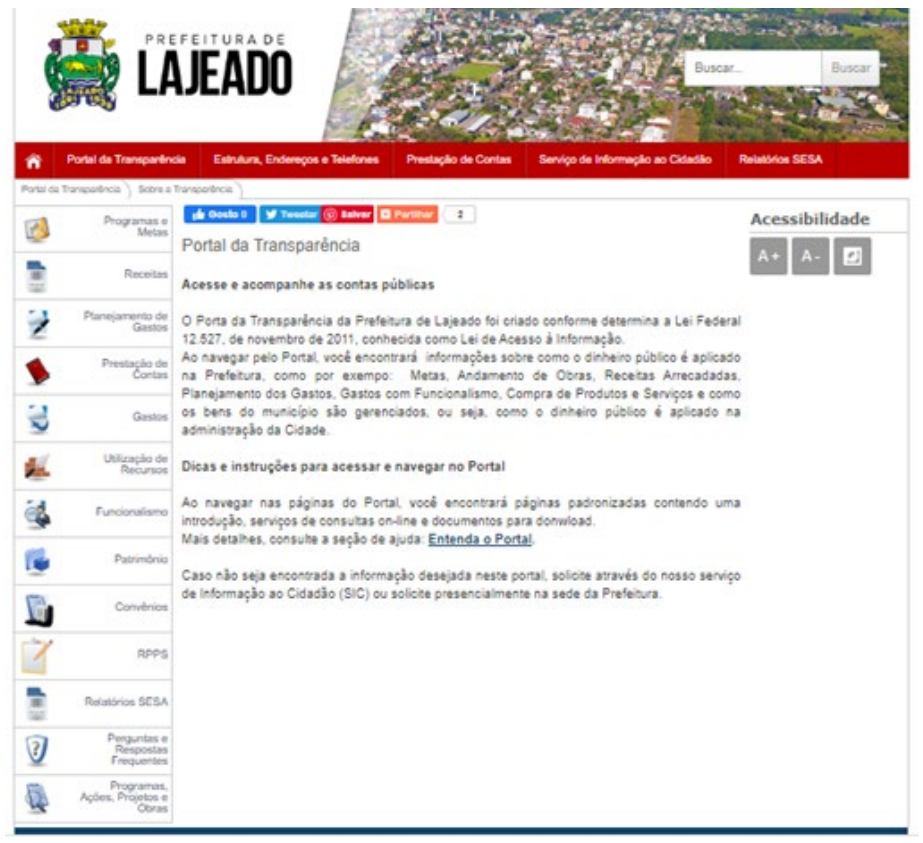

Fonte: Lajeado (2019). 
O portal pode ser acessado pelo site do município, http:/ /www.lajeado. rs.gov.br/, banner do Portal da Transparência, situado à direita da navegação.

Após essa coletas de dados, surgiu então a ideia de desenvolver um novo portal. Esse novo portal deveria apresentar de forma mais amigável e padronizada a informação para os cidadãos, e ainda prover um acesso cabível de reutilização dos dados para usuários técnicos. Após algumas tramitações de permissão por parte das autoridades competentes, foi autorizada a utilização dos dados da cidade para o projeto. Com os responsáveis da TI, o contato se estendeu via mensagens por e-mail, visando combinar as formas de envio dos dados.

Ficou acordado com a TI do município que as cargas iniciais de dados seriam advindas de arquivos físicos que a própria entidade já realizava a entrega para outros órgãos, a exemplo do arquivo PAD e do arquivo do Licitacon. Posteriormente os responsáveis ficaram de providenciar um acesso aos bancos de dados da organização, para que pudessem ser extraídos mais dados. Porém essa liberação de acesso aos bancos de dados não se deu até o fim do projeto, sendo a extração realizada então através de bases de dados simuladas.

Após a finalização do desenvolvimento do projeto, o mesmo teve sua utilização validada com usuários leigos e usuários técnicos a fim de verificar se os objetivos propostos foram atingidos.

\subsection{Tecnologias utilizadas para o desenvolvimento}

Como fruto do projeto, foram desenvolvidas duas aplicações, Portal e Integração, que serão mais detalhadas posteriomente. Ambas tiveram seu backend e frontend desenvolvidos de forma separada. Para isso, foram utilizadas Interfaces de Programação de Aplicações (APIs do inglês Application Programming Interfaces).

A API é um meio específico para usuários que desejam obter os dados sem ter a necessidade de navegar em uma página. Através dela, os usuários conectam seus programas diretamente às máquinas do Portal. Os dados informados são exatamente os mesmos que podem ser obtidos em tela, navegando pelo site (PORTAL DA TRANSPARÊNCIA, 2019).

As APIs do backend foram desenvolvidas utilizando o framework ASP.NET Core. Essa estrutura de aplicativos para Web foi desenvolvida pela Microsoft e segue o padrão de projetos MVC (Model, View e Controller). Apesar de pertencer à empresa criadora do Windows, a tecnologia também é suportada nos sistemas operacionais Linux e MacOS (MICROSOFT, 2019). A documentação para consumo das APIs foi feita utilizando a biblioteca Swagger UI.

As interfaces de interação com os usuários foram implementadas utilizando React js. Lançado em 2013 pelo Facebook, React js é uma biblioteca 
Javascript open source que se destaca pela sua característica declarativa, resultando em mais performance e menos código. Além do próprio Facebook, tem sido largamente utilizada em outras plataformas, como o Instagram (FEDOSEJEV, 2015).

Para o armazenamento dos dados, foram utilizados bancos de dados PostgreSQL. Esse SGBD foi criado em 1986 na Universidade de Berkeley, na Califórnia, e há mais de 30 anos se destaca por sua robustez e dedicação a comunidade open source. É um banco de dados relacional, compatível com os principais sistemas operacionais do mercado, e é manipulado através da linguagem SQL (POSTGRES, 2019).

\section{Resultados e Discussões}

O Capítulo 4 apresenta a aplicação que é o resultado do projeto, bem como os artefatos que envolveram o desenvolvimento da mesma. Ao final, ainda é apresentada uma discussão acerca da utilização da solução na área de gestão.

\subsection{Visão geral do projeto}

A fonte de dados para a projeto está em registros provenientes da própria Prefeitura. Porém, como ocorre na maioria das organizações, não há um núcleo central desses dados, eles são provenientes de inúmeros sistemas e módulos, e estão armazenados em diferentes formatos de arquivos e estruturas de dados. Dada essa vasta fonte de dados, se faz necessário um serviço que possa coletar informações nas mais diversas fontes. A API de Integração tem esse papel. Sendo previamente configurada ela pode interpretar e armazenar dados vindos de diferentes bases e arquivos. Essa configuração pode ser feita via uma interface gráfica, manuseável por um responsável técnico do município. Periodicamente, o responsável técnico executa as rotinas configuradas, e realiza a coleta dos dados.

Coletados, tratados e armazenados, os dados estão prontos para serem compartilhados com a Plataforma da Transparência. Essa comunicação se dá por meio de um novo serviço, a API da Plataforma da Transparência. Essa API permite, por meio de chamadas, que serviços autorizados postem novos conteúdos nas bases da plataforma.

Estando com as bases atualizadas, o Portal da Transparência e Dados Abertos divulga as informações de três formas: via listagens e filtros para o cidadão, via gráficos e dados estatísticos, e via API pública possibilitando a reutilização por usuários técnicos. A Figura 2 apresenta uma visão geral da arquitetura do Projeto. 
Figura 2 - Visão Geral do Projeto

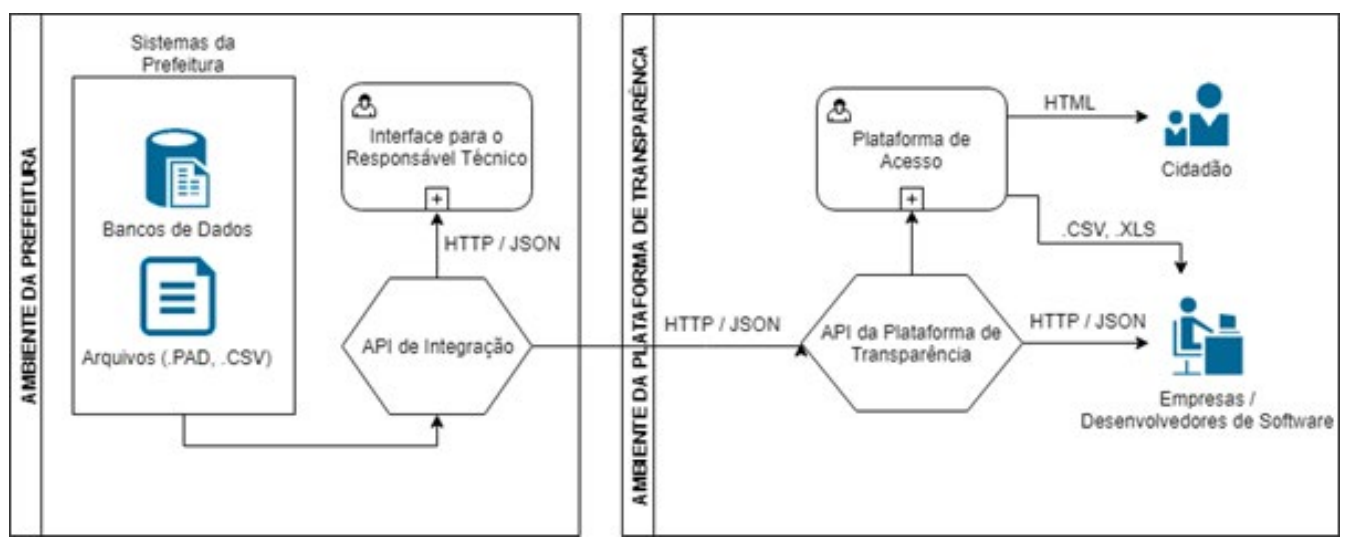

Fonte: Elaborado pelo autor (2019).

O Quadro 2 resume a função de cada componente da solução.

Quadro 2 - Componentes da Solução

\begin{tabular}{|c|c|}
\hline Componente & Descrição \\
\hline Sistemas da Prefeitura & $\begin{array}{l}\text { Servem de fonte de dados para o projeto. Formatos: bancos de } \\
\text { dados, arquivos .csv ou .txt. }\end{array}$ \\
\hline API de Integração & $\begin{array}{l}\text { Coleta dados nos sistemas da Prefeitura e realiza o envio para } \\
\text { a API da Plataforma da Transparência. }\end{array}$ \\
\hline écnico $\mathrm{o}$ & $\begin{array}{l}\text { Executa e configura os parâmetros necessários para a } \\
\text { Integração. }\end{array}$ \\
\hline & $\begin{array}{l}\text { Recebe dados das APIs de Integração e os provê para a página } \\
\text { web e chamadas públicas. }\end{array}$ \\
\hline Plataforma de Acesso & $\begin{array}{l}\text { Apresenta as informações através de formulários, listagens, } \\
\text { relatórios e gráficos. }\end{array}$ \\
\hline
\end{tabular}

Fonte: Elaborado pelo autor (2019).

\subsection{Conjuntos de Dados}

Inicialmente o projeto cobriu 4 conjuntos de dados da Prefeitura de Lajeado. Todos os registros obtidos são dados reais e existentes. A seguir, segue uma breve descrição de cada conjunto, e como ele foi obtido:

a. Convênios: acordos celebrados entre a Prefeitura e outras entidades para a prestação de serviços. Dados obtidos através de extração de dados no portal existente do município e posterior criação de banco de dados simulado. Dados de 2018 e 2019.

b. Empenhos: reservas orçamentárias para liquidação de despesas. Dados obtidos através do grupo de arquivos do PAD (Programa 
Autenticador de Dados), fornecido pelo município. O PAD é uma iniciativa pertencente ao SIAPC (Sistema de Informações para Auditoria e Prestação de Contas), e deve ser entregue pelos municípios ao TCE periodicamente. Dados de 2018 e 2019.

c. Licitações: concorrências e processos licitatórios promovidos pelo município. Dados obtidos através do grupo de arquivos do Licitacon (buscado no site do TCE), que é um arquivo que deve ser entregue pelos municípios ao TCE periodicamente. Dados de 2018 e 2019.

d. Servidores: dados dos servidores municipais e suas respectivas remunerações atuais, obtidas através de extração de dados no portal existente do município e posterior criação de banco de dados simulado.

\subsection{Interfaces do Sistema}

Ao acessar o Portal, o usuário é levado para a tela inicial da plataforma. Esta tela é direcionada ao acesso do Cidadão. Nela o usuário tem a opção de escolher entre os diferentes conjuntos de dados existentes: convênios, empenhos, licitações e servidores. Para cada conjunto, há a opção de visualização dos dados ou então de visualização dos gráficos. Paralelamente, há a opção de acesso a Área do Desenvolvedor, que é área destinada à usuários técnicos, que visam a reutilização dos dados. Esta segunda área será descrita ao longo do trabalho. A Figura 3 apresenta a interface da tela inicial, contendo as opções supracitadas. 
Figura 3 - Tela inicial do Portal da Transparência e Dados Abertos

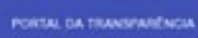

\section{Portal da Transparência}

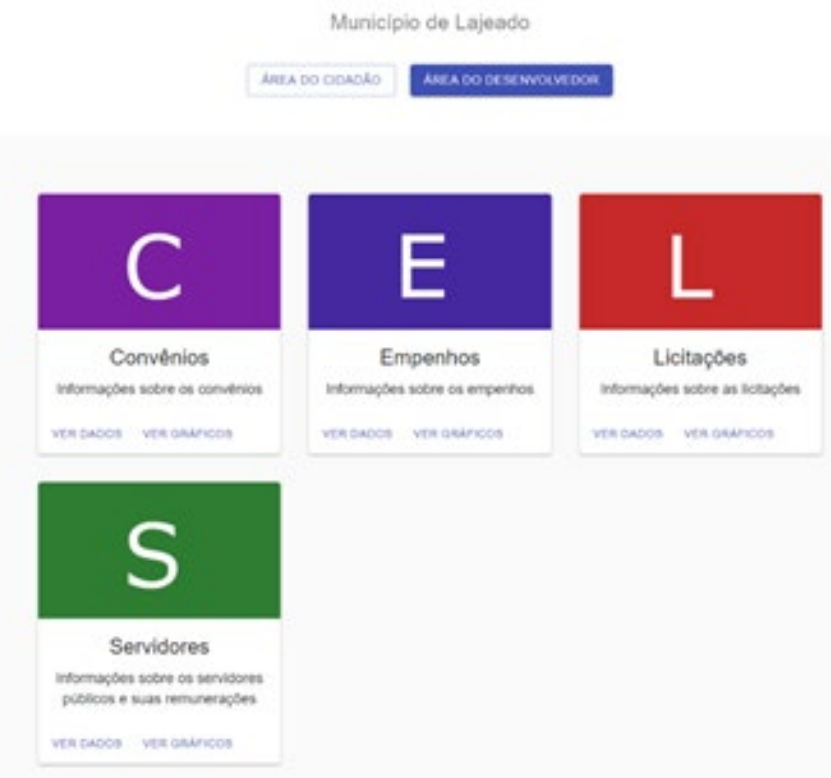

Fonte: Elaborado pelo autor (2019).

Optando pela visualização dos dados de um conjunto, o usuário é levado para a tela específica do grupo de informações selecionado. Nesta, é possível realizar diversos filtros nas informações, para então visualizar os registros através de uma listagem, ou então exportá-los em formato de arquivo .CSV. A Figura 4 demonstra a interface contendo informações dos Servidores Públicos, nela é possível filtrar através de campos como: nome do servidor, cargo do servidor, valor da remuneração inicial e final. Ao clicar no botão de ação da listagem, o usuário é levado para a página de detalhes do registro, que contém mais informações sobre o mesmo. 
Figura 4 - Interface dos Servidores Públicos

\section{PORTIAL OA TRANSPARENCIA}

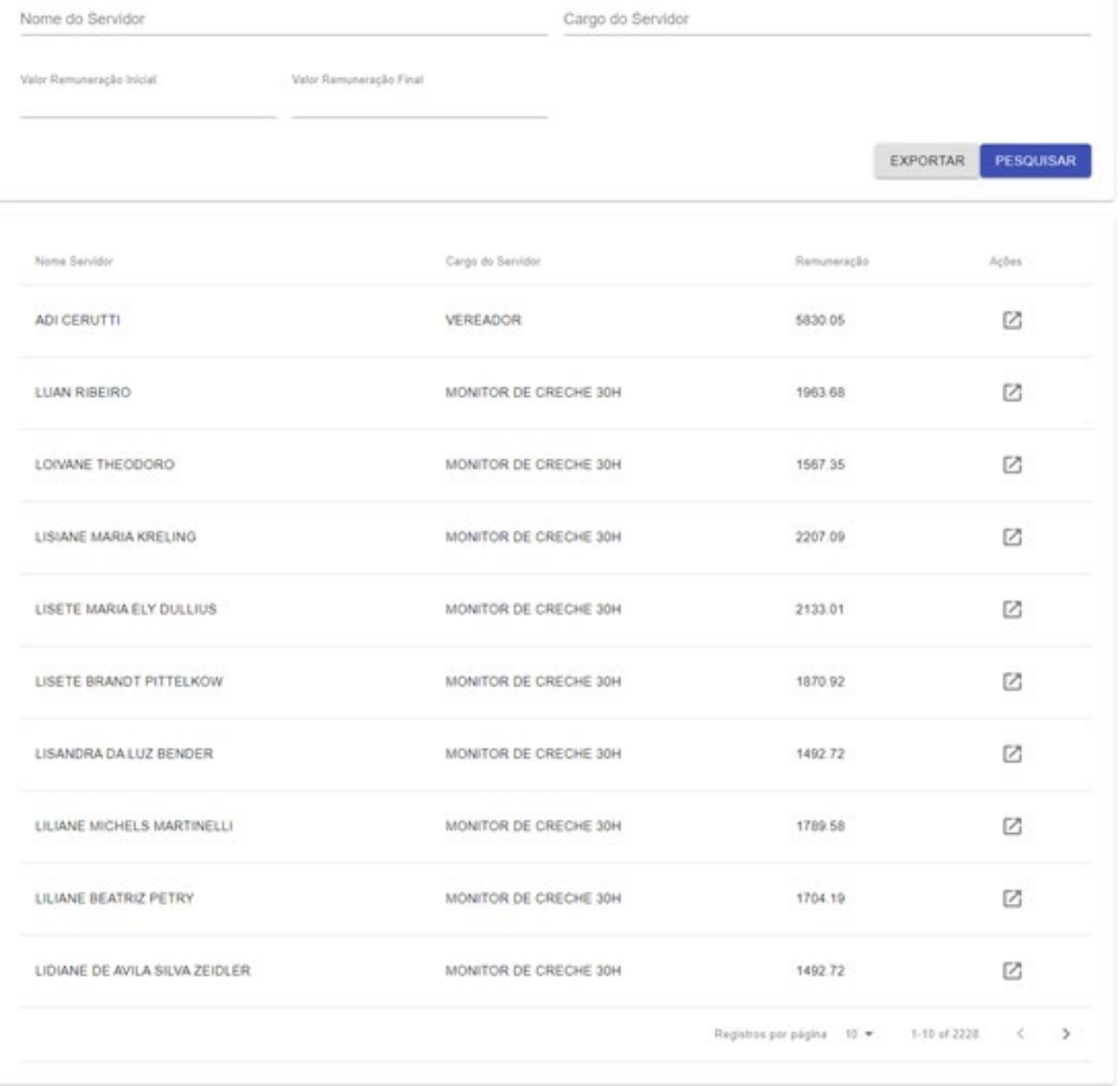

Fonte: Elaborado pelo autor (2019).

Para obter mais informações sobre um registro, o usuário pode optar por acessar a tela detalhes. A Figura 5 demonstra a exibição mais aprofundada de um registro de Licitação. No painel à esquerda são listadas mais informações sobre o dado. À direita é exibida uma tabela de registros relacionados. Essa tabela é fruto de uma identificação de dados que possuem algum tipo de cruzamento com o dado está sendo exibido. Esse cruzamento de informações facilita a interpretação e localização de mais informações por parte do usuário. No exemplo apresentado, são listados Empenhos que têm relação com a Licitação de Número 51. 
Figura 5 - Detalhes da Licitação

\section{PORTAL DA TRANSPARENCI}

Area do Cidadao / Licitaçces / Detahes da Licitaçao

Registros relacionados

Nimeno de veache

51 2018

Pregso Presencial

Fonte: Elaborado pelo autor (2019).

Para o Cidadão, há também a alternativa de visualização estatística de dados por meio da opção de Gráficos. Essa opção visa propiciar, de forma visual, que o usuário possa fazer inferências e interpretações mais amplas a respeito do conjunto de dados. A Figura 6, exibe a interface de visualização dos gráficos de Empenhos. Nela estão plotados dois gráficos: de números de Empenhos por ano e dos valores dos Empenhos por Órgão. 
Figura 6 - Gráficos dos Empenhos

\section{PORTAL OA TRANSPARENCIA}

Graficos dos Empenhos

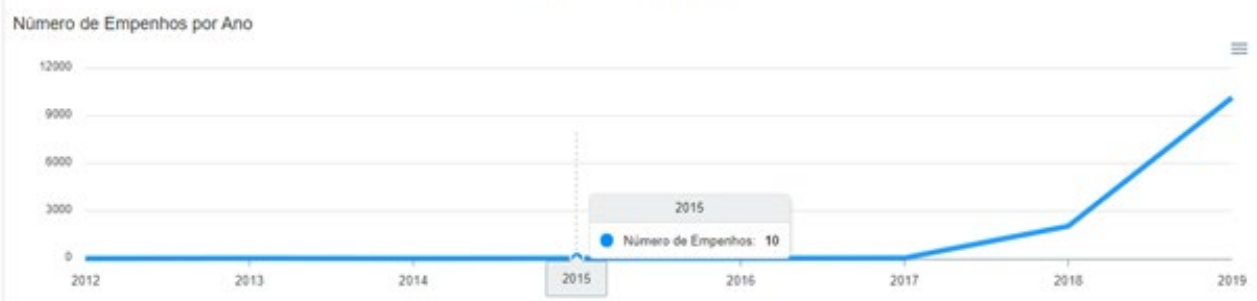

Valor dos Empenhos por Orgao

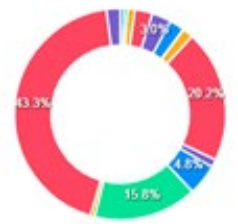

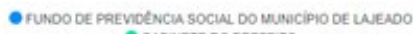
- QuBanete Do PREFEITO

- secaet traneruro, mart E Assist socula

- SECRETTARIA DA FAJENIDA

- secretaria de abminestracá

- SECRETARIA DE ACQICULTURA E ABASTECNESTO

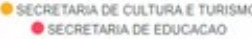

- secretafara de inoustrac e comercio

- sechetaria de veio amenevie

Fonte: Elaborado pelo autor (2019).

Além do acesso dedicado ao cidadão, há também um acesso pensado para as empresas e desenvolvedores de software. Essa utilização pode ser para inúmeros fins, como novos projetos, aplicações ou aplicativos. Como visto nas diretrizes dos Dados Abertos, esse consumo de informações deve poder ser feito de forma anônima e deve estar em formato padronizado, facilitando sua reutilização. Para isso, são disponibilizadas chamadas de API e suas respectivas documentações. A Figura 7 dispõe a tela de acesso a desenvolvedores e as chamadas que estão disponíveis para cada conjunto de dados. 
Figura 7 - Tela de Acesso a Desenvolvedores

$\Theta$ swagger $\quad$ Select a spec APIv1 $\sim$

\section{Portal da Transparência API ${ }^{\varpi}$}

\begin{tabular}{|c|c|}
\hline Convenios & $\checkmark$ \\
\hline 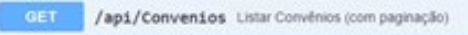 & \\
\hline /ap $1 /$ Convenios/ $/$ 1d $\}$ unter Convesio por io & \\
\hline Empenhos & $\checkmark$ \\
\hline /ap1/Empenhos unax tapensios (com pagisacilo) & \\
\hline /ap1/Empenhos/(1d) usar Emsento por io & \\
\hline Licitacoes & $\checkmark$ \\
\hline 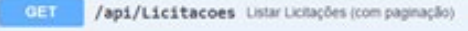 & \\
\hline 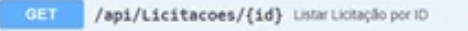 & \\
\hline Orgaos & $\checkmark$ \\
\hline /ap1/orgaos ustar Orplos & \\
\hline /ap1/orgaos/(1d) Latar Orgabo por io & \\
\hline Servidores & $\checkmark$ \\
\hline 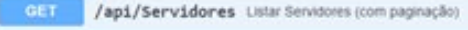 & \\
\hline /ap1/servidores $/($ id $\}$ Uats servoor por 10 & \\
\hline
\end{tabular}

Fonte: Elaborado pelo autor (2019).

Clicando sobre uma opção, é disponibilizado para o usuário, uma completa documentação para consumo da chamada. A Figura 8 exibe a documentação da chamada que lista Convênios. Percebe-se que são exibidos todos os parâmetros existentes para filtro (data assinatura inicial e final, convênio, convenente, valor inicial e final) e paginação (página e limite). Logo abaixo, há ainda a opção de simular a execução da chamada, visualizando seu status e retorno. Com isso se torna fácil a obtenção de dados em um formato adequado e passíveis de serem obtidos sempre que for necessário, facilitando com que desenvolvedores adaptem seus sistemas para a captação das informações. 
Figura 8- Documentação da chamada que lista Convênios

(4) swagger $\quad$ Seloct a spec APIn

\section{Portal da Transparência API ${ }^{\oplus}$}

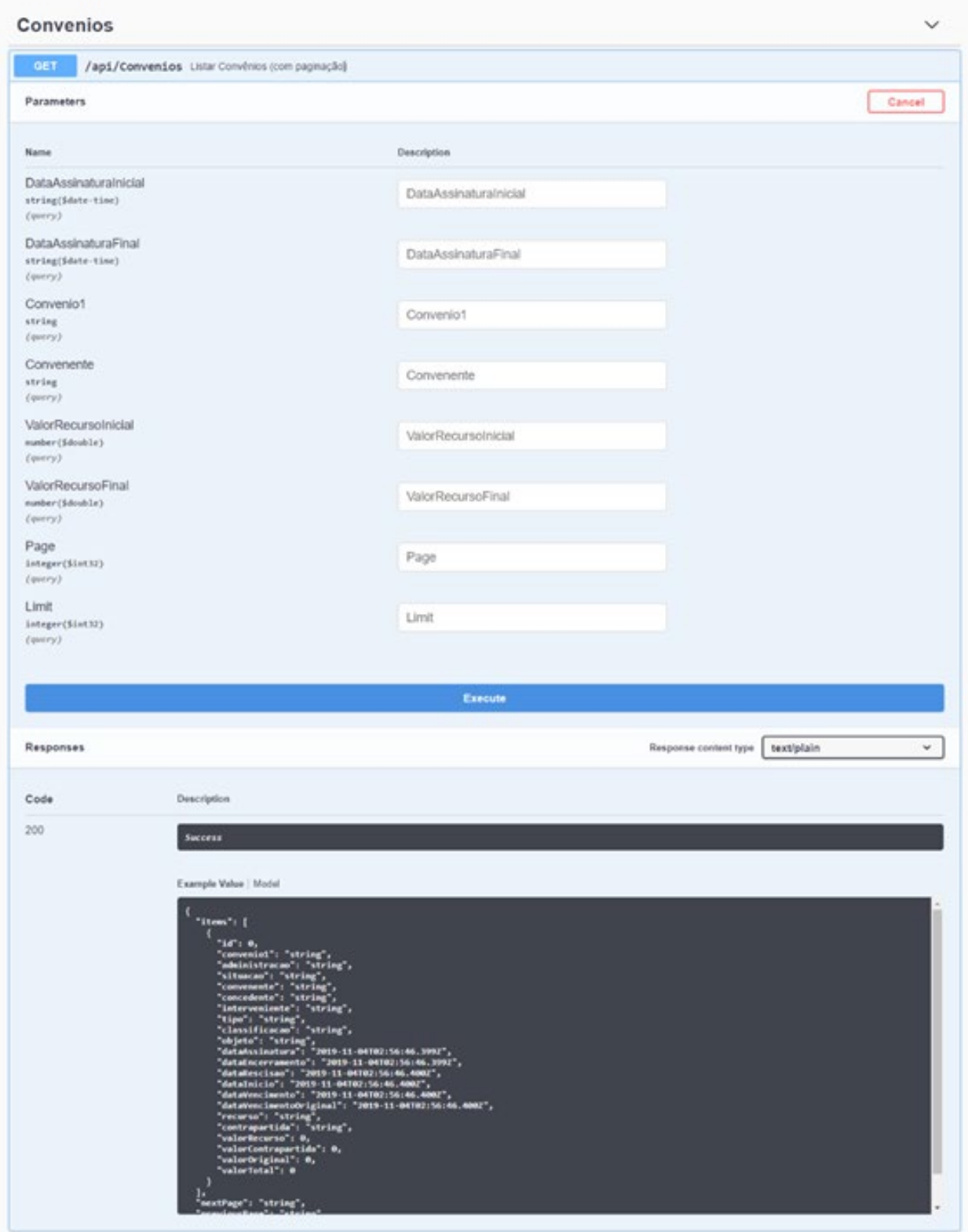

Fonte: Elaborado pelo autor (2019). 


\subsection{Validação}

Com o intuito de verificar a realização os objetivos propostos no presente trabalho, foi elaborado um plano de validação da solução desenvolvida. Para isso, 17 usuários foram submetidos a realizarem tarefas no Atual Portal da Transparência do Município de Lajeado, e em seguida convidados a realizarem as mesmas tarefas no Novo Portal da Transparência. Ao final da realização dos testes, foi proposto um questionário visando coletar dados quali-quantitativos a respeito das ferramentas..

Todas as tarefas que buscaram avaliar a usabilidade e facilidade dos dois portais apontaram para resultados melhores para o novo portal, como exemplo, temos o Gráfico 1 que aponta o resultado de uma das tarefas.

Gráfico 1 - Realização das Tarefas 1 e 2
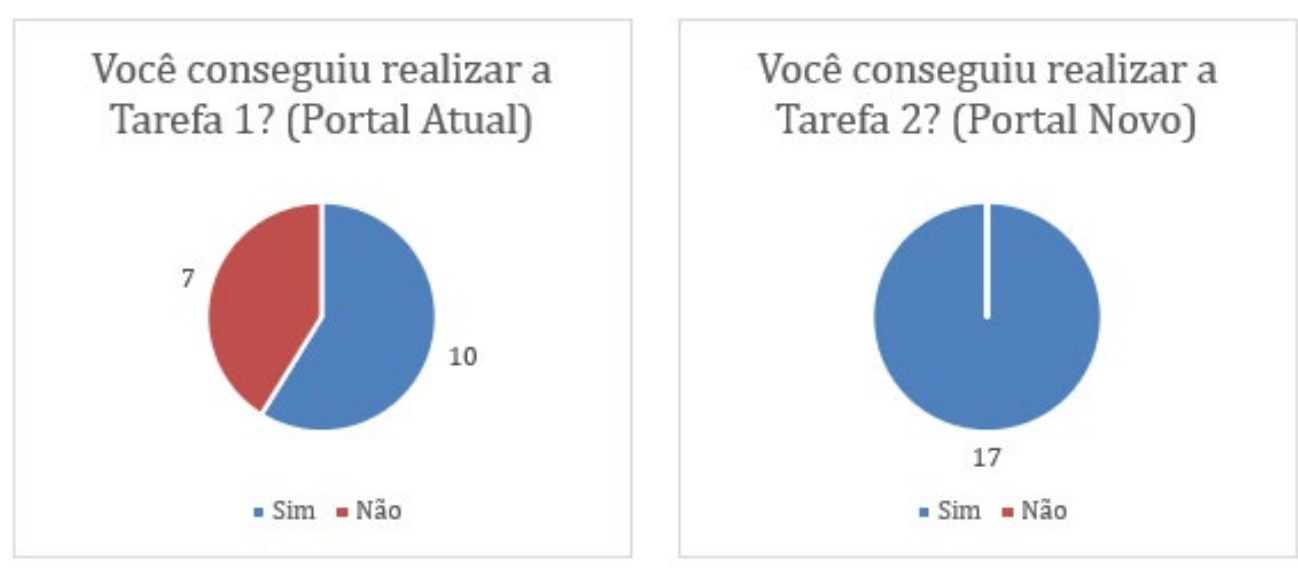

Fonte: Elaborado pelo autor (2019).

Para validar o Novo Portal quanto à sua capacidade de reutilização dos dados, foi questionado aos usuários, quais deles possuíam aptidão com desenvolvimento de software e consumo de APIs. Dentre os 17 usuários, 10 responderam possuir tal aptidão. Para estes, foi proposta uma tarefa extra. Esta tarefa pediu que os usuários, no Novo Portal, se redirecionassem à Área do Desenvolvedor da página. Estando nela, foi dado um passo a passo quanto ao consumo das informações nas APIs do Portal. O Gráfico 2 aponta que todos os usuários que se consideraram tecnicamente capazes conseguiram realizar a tarefa, e ainda demonstra que com certo grau de facilidade, dado que os 10 usuários apontaram facilidade ou muita facilidade na execução. 
Gráfico 2 - Tarefa para Usuários Técnicos

Você conseguiu realizar a

Tarefa 7? (Portal Novo)

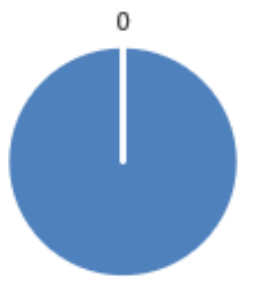

10

- Sim " Não

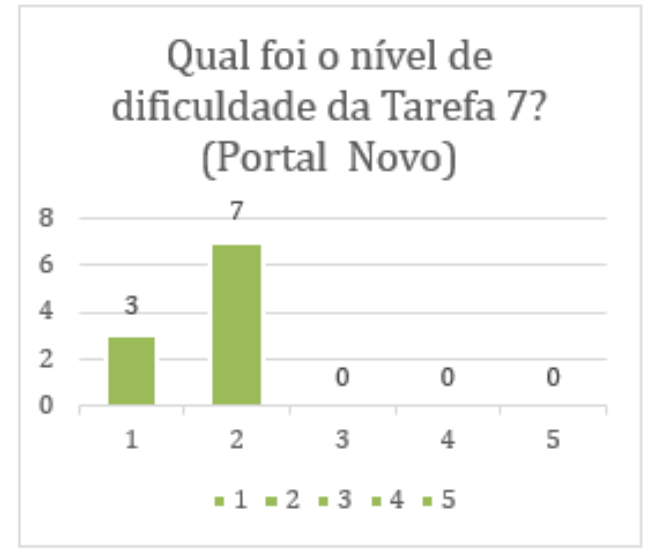

Fonte: Elaborado pelo autor (2019).

\section{Considerações finais}

A demanda por prestação de contas e transparência dos governos tem crescido constantemente por parte da sociedade brasileira. Em apoio a isso, leis e normativas têm sido impostas visando fortalecer essa cultura.

Todavia, a situação atual dos portais brasileiros não caminha nesta mesma direção. Páginas com interfaces pouco amigáveis ao cidadão e com baixo grau de reutilização dos dados podem afastar o interesse do cidadão pela fiscalização e pela utilização dos dados em novos projetos.

Dada essa problemática, o presente trabalho se propôs a oferecer uma ferramenta de captação de dados em arquivos e bases de dados da prefeitura, para posterior apresentação em formato amigável e reutilizável para o cidadão.

Durante o processo de validação com os usuários, a ferramenta demonstrou melhores níveis de usabilidade em comparação a situação atual dos portais. Dados coletados e comentários dos usuários comprovam que os usuários conseguiram acessar a informação de forma mais clara, rápida e intuitiva no Novo Portal. A validação ainda apontou viabilidade da reutilização dos dados em novas aplicações e iniciativas através das APIs. Usuário técnicos aprovaram a documentação e afirmaram conseguir consumir os dados da plataforma em forma reutilizável e padronizado.

O código fonte e documentação deste projeto ficarão disponíveis em formato aberto e público, para que futuros trabalhos sejam desempenhados a partir do mesmo. Sugere-se implantar a mesma solução em outros municípios, visto que a mesma foi arquitetada para funcionar em qualquer organização. Posteriormente instiga-se desenvolver uma ferramenta que possa cruzar 
dados entre os municípios, buscando por inconsistências ou suspeitas. Novos conjuntos de dados podem ser incorporados. E ainda podem ser desenvolvidos aplicativos e outras soluções que tenham como fonte de dados o projeto.

\section{Referências}

FEDOSEJEV, Artemij. React.js Essentials. Birgmingham, Inglaterra: Packt Publishing Ltd, 2015.

GARTNER. Conheça os 5 níveis de maturidade de Governos Digitais, 2018. Disponível em: <https://1doc.com.br/governo/2018/08/13/os-5-niveis-dematuridade-para-governos-digitais-gartner/>. Acesso em: 09 mai. 2019.

GLOBAL OPEN DATA INDEX. Place overview, 2016. Disponível em: $<$ https://index. okfn.org/place>. Acesso em: 24 mai. 2019.

GRÖNLUND, Åke. Electronic Government: Design, Applications \& Management. Hershey, EUA: Idea Group Publishing, 2002.

GRÖNLUND, Åke; HORAN, Thomas A. Introducing e-Gov: History, Definitions, and Issues. Communications of the Association for Information Systems: Vol. 15 , Artigo 39, [S. 1.], 2005.

JANSSEN, Marijn; CHARALABIDIS, Yannis; ZUIDERWIJK, Anneke. Benefits, Adoption Barriers and Myths of Open Data and Open Government. Information Systems Management, [S. 1.], 05 out. 2012.

MICROSOFT. ASP.NET MVC Pattern, 2019. Disponível em: < https:/ / dotnet. microsoft.com/apps/aspnet/mvc >. Acesso em: 23 de mai. 2019.

OPEN GOV DATA. Eight principles of open government data, 2007. Disponível em: <https://public.resource.org/8_principles.html>. Acesso em: 14 mai. 2019.

PORTAL DA TRANSPARÊNCIA. API de dados, 2019. Disponível em: $<$ http://www. portaltransparencia.gov.br/api-de-dados >. Acesso em: 29 mai. 2019.

POSTGRESQL. What is PostgreSQL? 2019. Disponível em: <https:/ / www.postgresql. org/about/https:/ /www.postgresql.org/>. Acesso em: 23 de mai. 2019.

RIBEIRO, Claudio J. S.; ALMEIDA, Reinaldo F. de. Dados Abertos Governamentais (Open Government Data): Instrumento Para Exercício De Cidadania Pela Sociedade. In: XII ENANCIB - Encontro Nacional De Pesquisa Em Ciência Da Informação, 2011, Brasília. 